\title{
Pemberdayaan pada Penderita Diabetes Tipe 2 dan Kader Kesehatan dalam Pelaksanaan Program Pos Binaan Terpadu Penyakit Tidak Menular (Posbindu PTM)
}

\author{
Arief Andriyanto \\ Departemen Keperawatan Komunitas, \\ STIKes Bina Sehat PPNI Mojokerto \\ E-mail: ners.arif91@gmail.com
}

\section{Dwi Cahya Rahmadiyah}

Departemen Keperawatan Komunitas, Fakultas Ilmu Keperawatan, Universitas Indonesia

\section{Article History:}

Received: 2019-10-16

Revised: 2020-04-17

Accepted: 2020-05-31

Keywords: Health Cadre

Empowerment, Type 2 Diabetes

Mellitus, Posbindu PTM

\author{
Etty Rekawati \\ Departemen Keperawatan Komunitas, \\ Fakultas Ilmu Keperawatan, \\ Universitas Indonesia
}

\begin{abstract}
Diabetes mellitus is classified as a noncommunicable disease which has been estimated to have increased, so a risk factor control program recommended by the Ministry of Health is required according to the DM management pillar. Health cadre empowerment is also needed to actively support noncommunicable diseases programs. The purpose of this community empowerment was to change the behavior of people with type 2 diabetes in glucose control and improve the health cadres' skills in Posbindu PTM activities. The program was carried out in October 2018 until March 2019. The targets were: 86 type 2 diabetes patients, 24 cadres in Cisalak Pasar Kelurahan, 120 cadres in Cimanggis District, and 293 cadres in Depok City. The results chowed that patients could control their glucose and health cadres experienced improved skills. The role of community nurses is continuously needed to provide appropriate interventions to the patients.
\end{abstract}

\section{Pendahuluan}

Kota Depok merupakan salah satu kota yang menyumbang prevalensi diabetisi terbanyak di Jawa Barat. Data penyakit diabetes mellitus mengalami peningkatan dari tahun 2016 sebanyak 21.971 kasus menjadi 29.475 kasus di tahun 2018'. Hasil survei di Wilayah Kerja UPF Puskesmas Cisalak Pasar Kecamatan Cimanggis Kota Depok pada 86 pasien diabetes mellitus. Data pengetahuan pasien terkait penyakit diabetes mellitus

1 Dinkes, “Profil Kesehatan Kota Depok 2015” (2016). 
ENGAGEMENT

Jurnal Pengabdian kepada Masyarakat

Volume 04, Number 01, May, 2020, pp. 201 - 211

terdapat $11.6 \%$ pengetahuan baik, $46.5 \%$ pengetahuan cukup, $41.9 \%$ pengetahuan kurang, 43\% sikap positif, 57\% sikap negatif, 45.3\% keterampilan baik dan $54.7 \%$ keterampilan buruk.

Peningkatan yang terjadi disebabkan oleh beberapa faktor, namun penyakit ini dapat dikendalikan melalui perubahan perilaku. Perilaku yang baik akan menjadikan penderita dapat tetap melakukan pengendalian gula darahnya, dalam hal ini perilaku yang disarankan adalah manajemen diri yang baik. Manajemen diri penderita diabetes meliputi pencarian informasi melalui edukasi kesehatan, perencanaan makan atau diet, melakukan aktivitas fisik secara teratur, minum obat/insulin, pemantauan rutin kadar gula darah, melakukan perawatan kaki, dan kontrol stress yang berlebihan ${ }^{2}$. Manajemen diri diabetes yang baik menjadikan penderita dapat mempertahankan atau kontrol glukosa dalam batas normal, karena cara ini sangat penting untuk pengelolaan diabetes melitus. Diet juga merupakan cara yang tepat dan memiliki dampak yang besar dalam menstabilkan kadar glukosa darah penderita. ${ }^{3}$

Manajemen diri diabetes mengacu pada konsep bahwa setiap orang secara sistematis harus terlibat dalam kondisi manajemen medis dan non-medisnya. Tantangannya telah terlihat di sini adalah apakah bukti ilmiah mendukung strategi edukasi manajemen diri pada diabetes mellitus sesuai dengan kebutuhan pasien ${ }^{4}$. Beberapa peneliti sebelumnya telah menunjukkan bahwa pendidikan manajemen diri adalah teknik yang efektif untuk kontrol glikemik. Diabetes Self-Management Education (DSME) merupakan intervensi pendidikan manajemen diri diabetes mellitus terkait pengaturan diet dan aktifitas fisik yang bertujuan untuk kontrol gula darah. ${ }^{5}$ Intervensi ini juga telah dibuktikan berdasarkan hasil penelitian yang menemukan bahwa status psikologis dan glukosa darah pasien dengan diabetes yang menerima pendidikan manajemen diri meningkat secara signifikan.

Meskipun sampai batas tertentu pasien diabetes disarankan secara rutin untuk mengikuti diet yang sehat dan perubahan pola makan seperti modifikasi dalam pola makan. Diabetes melitus tipe 2 biasanya dikaitkan dengan peningkatan prevalensi,

2 Sanbao Chai et al., "The Effect of Diabetes Self-Management Education on Psychological Status and Blood Glucose in Newly Diagnosed Patients with Diabetes Type 2," Patient Education and Counseling 101, no. 8 (2018): 1427-1432; Emiko Kamitani, Yoshimi Fukuoka, and Carol Dawson-Rose, "Knowledge, Self-Efficacy, and Self-Perceived Risk for Cardiovascular Disease among Asians Living With HIV: The Influence of HIV Stigma and Acculturation," Journal of the Association of Nurses in AIDS Care 26, no. 4 (2015): 443-453.

${ }^{3}$ Ali Reza Soltanian, Shiva Borzouei, and Mohammad Afkhami-Ardekan, "Design, Developing and Validation a Questionnaire to Assess General Population Awareness about Type II Diabetes Disease and Its Complications," Diabetes and Metabolic Syndrome: Clinical Research and Reviews 11 (2017): S39-S43.

4 Danita Alfred et al., "Preparing for Disasters: Education and Management Strategies Explored," Nurse Education in Practice 15, no. 1 (2015): 82-89.

${ }^{5}$ Deldar Morad Abdulah et al., "Impacts of Self-Management Education on Glycaemic Control in Patients with Type 2 Diabetes Mellitus," Diabetes and Metabolic Syndrome: Clinical Research and Reviews 12, no. 6 (2018): 969-975. 
risiko depresi dan kecemasan, yang dapat mempengaruhi kadar glukosa darah. Melalui pendidikan, suasana hati pasien yang baru didiagnosis dengan diabetes membaik, menghasilkan kontrol glukosa darah yang lebih baik. Dampak dari intervensi Diabetes Self-Management selama tiga bulan yang dilakukan pada pasien dengan diabetes tipe 2 dapat kontrol glikemik. Bentuk kegiatan intervensi Diabetes Self-Management Education (DSME), sebagai berikut: (1) Minggu pertama; pengantar diabetes mellitus, jenis DM, faktor risiko, pencegahan, dan komplikasi diabetes melitus tipe 2 termasuk neuropati, nefropati, retinopati, kebutaan, penglihatan kabur, borok kaki dan amputasi, dan masalah kardiovaskular; (2) Minggu kedua; Jenis aktivitas fisik diperlukan untuk mencegah komplikasi penyakit (berjalan, jogging, senam kaki); (3) Minggu ketiga; tujuan gizi manajemen diabetes, makanan sehat dan tidak sehat untuk diabetes melitus tipe 2 dengan fokus pada pencegahan komplikasi melalui modifikasi gaya hidup. Selain itu, pengalaman klien, perilaku diet, dan aktivitas fisik dibahas secara rinci pada setiap sesi pendidikan dan dilatih tentang tes glukosa harian juga. ${ }^{6}$

Kegiatan yang dilakukan tidak hanya untuk penderita diabetes, akan tetapi juga melibatkan peran serta masyarakat yang dalam hal ini adalah seorang kader kesehatan. Partisipasi masyarakat atau seorang kader kesehatan sangat berpotensi dalam kelancaran kegiatan, sehingga kemampuan kader kesehatan dapat digali secara efektif. Program pengendalian penhakit DM diberikan berdasarkan komitmen bersama dari seluruh elemen masyarakat, termasuk penderita dan kader kesehatan melalui kegiatan pos pembinaan terpadu penyakit tidak menular. Pengembangan pos pembinaan terpadu penyakit tidak menular merupakan bagian integral dari sistem pelayanan kesehatan, dan memberikan berbagai upaya promotif dan preventif serta pola rujukannya berdasarkan persoalan penyakit tidak menular yang ditemukan di masyarakat. Pos pembinaan terpadu penyakit tidak menular akan berjalan dengan baik, apabila disiapkan tenaga (kader kesehatan) yang akan mengelola dan melaksanakan kegiatan pos pembinaan terpadu penyakit tidak menular. Untuk hal tersebut, maka diperlukan penguatan penerapan sistem 5 meja dalam pelaksanaannya. ${ }^{7}$ Sebagaimana mestinya untuk mendukung program pemerintah "Indonesia Sehat" diperlukan perbaikan dan pengembangan melalui program riset pengabdian masyarakat ini untuk mengubah perilaku penderita diabetes dalam kontrol glukosa dan meningkatkan keterampilan seorang kader kesehatan dalam pelaksanaan pos pembinaan terpadu penyakit tidak menular.

${ }^{6}$ Ibid.

7 Ekowati Rahajeng, "Pedoman Teknis Surveilans Faktor Risiko PTM Berbasis Posbindu," Kemenkes RI, no. Maret (2014). 
ENGAGEMENT

Jurnal Pengabdian kepada Masyarakat

Volume 04, Number 01, May, 2020, pp. 201 - 211

\section{Metode}

Riset pengabdian ini menggunakan perpaduan metode Community-Based Research (CBR) dan sistem teknologi informasi yang terintegrasi. Pengabdian masyarakat ini dilakukan di Kelurahan Cisalak Pasar Kecamatan Cimanggis Kota Depok selama 6 bulan, Oktober 2018 - Maret 2019. Sasaran dalam pengabdian ini penderita diabetes tipe 2 dan kader kesehatan di Kota Depok yang diberikan perlakuan/intervensi pada setiap sesi pertemuan. Media yang digunakan pengabdi berupa modul, buku kerja, leaflet, sterofoam, food model, kelereng, musik instrumental.

Kegiatan promotif dan preventif dengan upaya penyebaran informasi dan edukasi yang efektif melalui strategi intervensi keperawatan komunitas mengenai penyakit diabetes melitus perlu dilakukan, karena edukasi untuk dewasa diabetes melitus merupakan kegiatan yang bertujuan merubah perilaku untuk dapat melakukan pencegahan terjadinya komplikasi. ${ }^{8}$ Pengetahuan, sikap, dan keterampilan seseorang akan meningkat apabila dirinya dilakukan pendampingan untuk diberikannya suatu kegiatan atau cara menstimulasi dirinya berupa kegiatan-kegiatan yang memicu untuk menimbulkan kesadaran dirinya. Contoh dalam hal ini adalah intervensi yang dikembangkan berdasarkan teori Health Promotion Model dan intervensi Diabetes SelfManagement Education (DSME) yang dapat diberikan kepada diabetisi khususnya untuk meningkatkan kesadaran diri dan selanjutnya akan menciptakan manajemen diri yang baik untuk perawatan dirinya dalam kontrol gula darah. Oleh karena itu, memang dibutuhkan suatu intervensi keperawatan ditatanan pelayanan kesehatan yang diberikan kepada penderita diabetes tipe 2 dengan upaya promotif dan preventif pengendalian penyakit.

\section{Tahapan Pelaksanaan}

Pelaksanaan pemberian intervensi, sebagai berikut: sesi 1 terkait edukasi kesehatan penyakit diabetes mellitus dengan metode menonton video edukasi, diskusi dan evaluasi buku kerja yang dilaksanakan 1 kali pertemuan pada bulan November minggu pertama (media intervensi: video edukasi, leaflet, lembar balik), pelatihan kader kesehatan dalam penerapan sistem 5 meja posbindu PTM dilakukan 1 kali pelatihan dan 2 kali supervisi. Sesi 2: Skrining kesehatan: skrining faktor risiko diabetes mellitus dengan metode support group oleh kader kesehatan kepada masyarakat, demonstrasi dan re-demonstrasi pada pelatihan pengisian google form pada kader kesehatan yang dilaksanakan 2 kali pertemuan pada bulan November minggu kedua dan Januari minggu

${ }^{8}$ Marcia Stanhope and Jeanette Lancaster, Foundations of Nursing in The Community: CommunityOriented Practice (by Mosby, Inc., an affiliate of Elsevier Inc., 2016); Nola Pender, Carolyn Murdaugh, and Mary Ann Parsons, Health Promotion in Nursing Practice, ed. Erin Sullivan, Seventh. (United States of America: Julie Levin Alexander, 2015). 
pertama (media intervensi: form skrining DM, google form, laptop dan LCD). Sesi 3-5: Manajemen nutrisi: (1) makanan sehat dan tidak sehat pasien DM dengan metode permainan kuis siapa berani dan evaluasi buku kerja yang dilaksanakan 2 kali pertemuan pada bulan November minggu ketiga dan keempat (media intervensi: power point, gambar contoh makanan, sterofoam, panduan permainan, print out ppt, bulpoint dan push pin); (2) menghitung kebutuhan kalori tubuh dilakukan dengan tutorial yang dilaksanakan 1 kali pertemuan pada bulan Desember minggu pertama (media intervensi: buku kerja); (3) menyusun menu makan sehari dengan metode demonstrasi dan re-demonstrasi, sertaevaluasi buku kerja yang dilaksanakan 1 kali pertemuan pada bulan Desember minggu kedua dan evaluasi buku kerja Januari minggu ketiga (media intervensi: buku kerja, food model, piring makananku). Sesi 6-7: Peningkatan latihan: (1) senam kaki diabetes dengan metode demonstrasi dan re-demonstrasi yang dilakukan selama 5 kali pertemuan pada bulan Januari minggu pertama, kedua, ketiga dan Februari minggu pertama dan kedua (media intervensi: leaflet, kursi, koran); (2) senam cerdik dilakukan bersama kader kesehatan dan masyarakat setiap minggu sekali (media intervensi: sound system, musik senam cerdik gerakan Kota Depok). Sesi 8: relaksasi otot progresif dan terapi musik dilakukan dengan metode pendampingan perawat spesialis keperawatan komunitas selama 5 kali pertemuan pada bulan Februari minggu ketiga sampai dengan Maret minggu ketiga (media intervensi: leaflet, musik instrumental "the give angels" dan sound system). Sesi 9: pelatihan kader kesehatan melakukan pengkajian skrining faktor risiko diabetes kepada masyarakat. Sesi 10: pelatihan pelaksanaan sistem 5 meja posbindu PTM dan sistem pelaporan pelaksanaan posbindu PTM oleh kader kesehatan.

\section{Hasil dan Diskusi}

Hasil dari penerapan inovasi intervensi terhadap kontrol gula darah dewasa dengan diabetes mellitus di Kelurahan Cisalak Pasar Kecamatan Cimanggis Kota Depok disajikan dalam Gambar 1. Sedangkan hasil dari peningkatan keterampilan kader kesehatan dalam pelaksanaan posbindu PTM di Kelurahan Cisalak Pasar Kecamatan Cimanggis Kota Depok disajikan dalam Gambar 2.

Pelaksanaan intervensi EMAS selama 3 bulan dalam praktek residensi keperawatan komunitas melibatkan keluarga sebagai sumber perawatan terdekat bagi anggota keluarganya. Intervensi dilakukan 3 sesi dalam 3 minggu terkait dasar penyakit diabetes mellitus, dan dilanjutkan selama 3 bulan terkait manajemen nutrisi dan aktivitas fisik. Manajemen nutrisi diberikan selama 6 minggu, 1 minggu 1 sesi dengan materi sesi 1; diet diabetes mellitus, sesi 2; makanan yang dianjurkan, dibatasi, dan dihindari, sesi 3; penghitungan kebutuhan kalori, sesi 4; menyusun menu makan sehari, dan 2 minggu berikutnya penderita diabetes mellitus melatih diri menggunakan buku 
ENGAGEMENT

Jurnal Pengabdian kepada Masyarakat Volume 04, Number 01, May, 2020, pp. 201 - 211

kerja dalam mencatat terkait makanan apa saja yang telah dikonsumsi. Aktivitas fisik berupa senam kaki dan terapi kelereng diberikan selama 6 minggu 12 sesi. Pemantauan kepatuhan melakukan intervensi dan pengukuran gula darah dilakukan saat kunjungan rumah dan buku kerja.

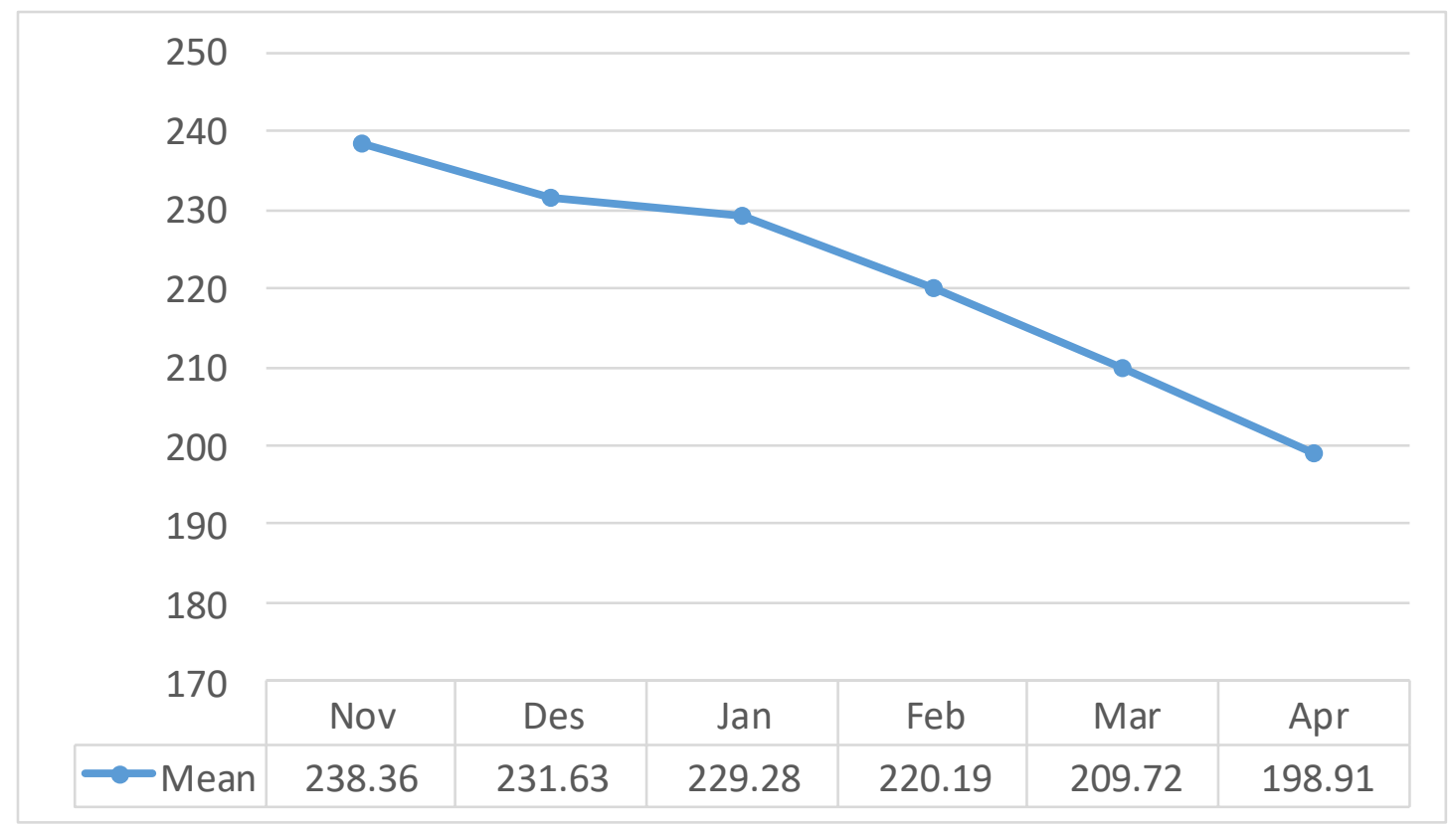

Gambar 1. Gula Darah Penderita DM Tipe 2

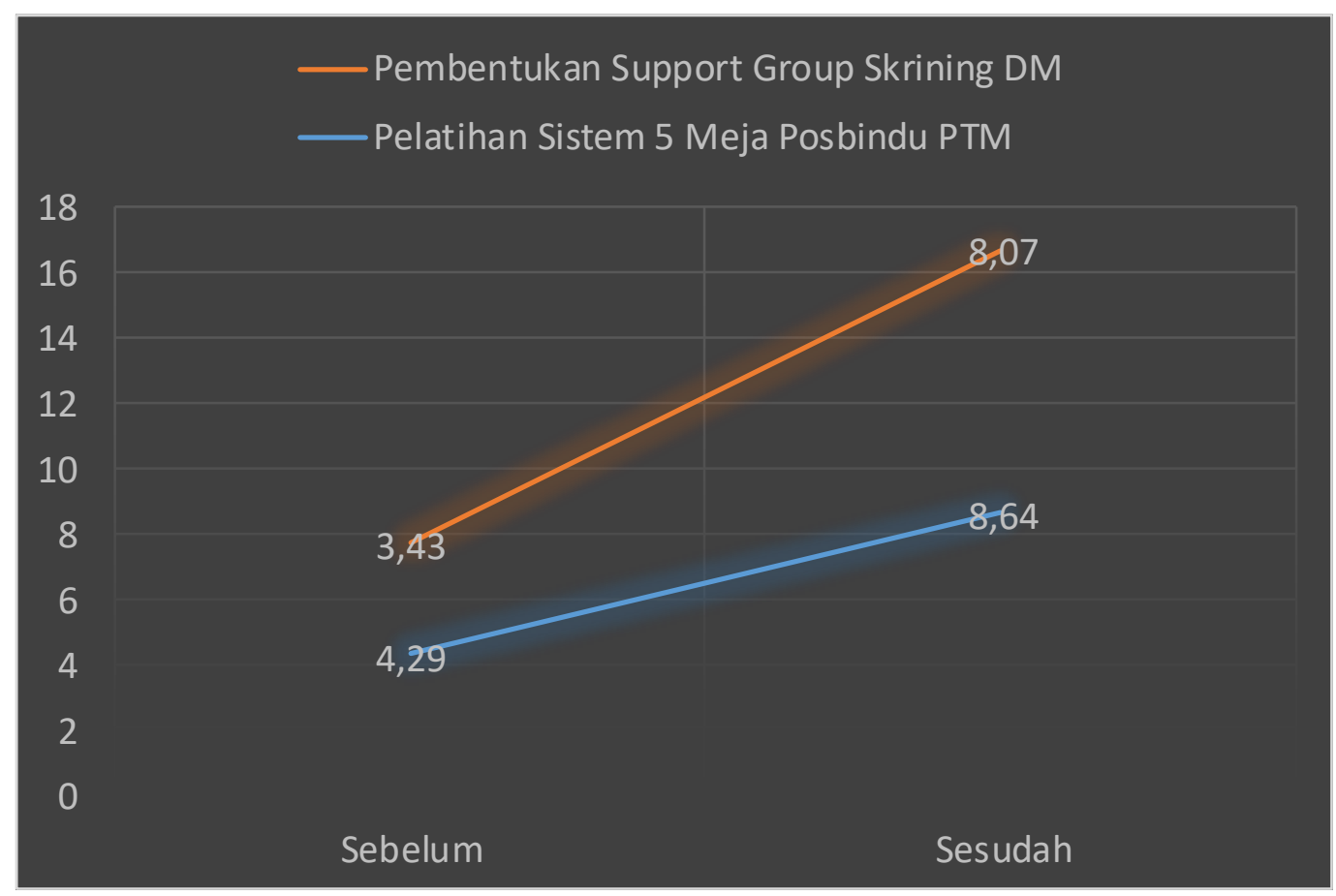

Gambar 2. Keterampilan Kader Kesehatan 
Edukasi dengan tujuan promosi hidup sehat perlu dilakukan sebagai bagian dari upaya pencegahan dan pengendalian penyakit diabetes melitus. Asosiasi Diabetes Internasional percaya bahwa untuk mencegah terjadinya komplikasi diabetes atau penyakit semakin berkelanjutan, maka diperlukannya sebuah pendidikan kesehatan terhadap perilaku pengelolan diri diabetisi. ${ }^{9}$ Penelitian terkait pendidikan kesehatan didapatkan Diabetes self-management education (DSME) memainkan peran kunci dalam memberdayakan orang dengan diabetes mellitus untuk tetap selalu terlibat dalam kegiatan dan melakukan perubahan gaya hidup, yang telah terbukti meningkatkan hasil kesehatan. DSME adalah intervensi yang memberikan fasilitas pada penderita untuk menggali pengetahuan, sikap dan keterampilan penderita dalam memperbaiki manajemen dirinya. DSME sangat perlu dilakukan kepada diabetisi secara berkala, hal ini juga sudah sejalan dengan program Kementrian Kesehatan. ${ }^{10}$

Selain edukasi kesehatan yang diberikan dalam inovasi ini, mahasiswa juga mengajarkan terkait manajemen nutrisi yang meliputi; pola makan, makanan yang dianjurkan, dibatasi, dan dihindari, penghitungan kebutuhan kalori tubuh, serta menyusun menu makan sehari. Prinsip dalam pengaturan makan penderita diabetes sama seperti makanan pada umumnya yang dikonsumsi oleh masyarakat, yaitu dengan menu gizi seimbang dan kalori yang dibutuhkan penderita. Dewasa diabetes mellitus perlu diberikan penekanan mengenai pentingnya diet 3J yang meliputi keteraturan jadwal, jenis dan jumlah, terutama pada penderita yang menggunakan terapi insulin. ${ }^{11}$ Intervensi manajemen nutrisi ini juga memiliki hasil yang sama dengan penelitian terkait konseling nutrisi untuk penderita diabetes tipe 2, dan hasilnya juga terbukti dapat meningkatkan pengetahuan responden dan keterampilan dalam menentukan gizi seimbang. ${ }^{12}$

Aktivitas fisik juga diberikan oleh mahasiswa residensi setelah manajemen nutrisi diberikan selama 5 pertemuan. Aktivitas fisik yang diberikan pada diabetisi berupa senam cerdik dan senam kaki diabetes. Senam cerdik merupakan latihan yang dipelopori oleh Dinas Kesehatan Kota Depok untuk mencegah dan mengendalikan penyakit diabetes mellitus, sedangkan senam kaki diabetes merupakan kegiatan promotif dan preventif yang diberikan kepada diabetisi tipe 2 untuk meningkatkan

${ }^{9}$ Dina L.G. Borzekowski, "A Quasi-Experiment Examining the Impact of Educational Cartoons on Tanzanian Children," Journal of Applied Developmental Psychology 54, no. March 2017 (2018): 53-59.

${ }^{10}$ Lifeng Fan, R N Cde, and Souraya Sidani, "Factors Influencing Preferences of Adult with Type 2 Diabetes for Diabetes Self-Management Education Interventions," Canadian Journal of Diabetes (2018).

11 Nor H. Ishak et al., "Diabetes Self-Care and Its Associated Factors among Elderly Diabetes in Primary Care," Journal of Taibah University Medical Sciences 12, no. 6 (2017): 504-511.

12 Scott A Davis et al., "Patient Education and Counseling Patient Adoption of an Internet Based Diabetes Medication Tool to Improve Adherence : A Pilot Study," Patient Education and Counseling 100, no. 1 (2017): 174-178. 
sensitivitas pada kaki agar dapat mencegah terjadinya komplikasi yaitu luka pada kaki dan melancarkan peredaran darah pada kaki. Terdapat manfaat lain yang dirasakan dewasa diabetes melitus setelah melakukan senam kaki secara teratur. Hasil yang sama didapatkan oleh penelitian sebelumnya terdapat perubahan atau penurunan kadar gula pasien dengan diabetes setelah diberikan intervensi yaitu senam kaki. ${ }^{13}$

Peningkatan resiko penyakit diabetes melitus pada kondisi stres disebabkan oleh produksi hormon kortisol secara berlebihan. Produksi hormon kortisol menyebabkan nafsu makan penderita berlebih, sehingga diperlukan metode untuk mengurangi stres yang terjadi. ${ }^{14}$ Pengelolaan stres yang efektif dalam menurunkan tingkat stres dan kontrol gula darah diabetes melitus dengan cara latihan relaksasi otot progesif dan terapi musik. Relaksasi otot progresif memiliki berbagai manfaat, hal ini dapat dilihat dari hasil penelitian sebelumnya terkait pengaruh terapi relaksasi otot progresif juga didapatkan hasil bahwa terapi ini sangat efektif menurunkan stres dan gula darah dengan nilai signifikan $0.003 .^{15}$

\section{Kesimpulan}

Pengabdian masyarakat ini mendapatkan hasil bahwa penderita diabetes tipe 2 dapat kontrol gula darahnya melalui intervensi EMAS (edukasi, manajemen nutrisi, aktivitas fisik, dan pengelolaan stres). Oleh karena itu, dalam memberikan intervensi harus disesuaikan dengan penatalaksanaan penyakit dan kebutuhan penderita. Program terkait upaya promotif dan preventif perlu ditinjau kembali dengan lebih memperhatikan aspek karakteristik dewasa dengan diabetes mellitus dan wilayah sebagai percontohan. Dinas kesehatan juga perlu melakukan integrasi terkait edukasi kesehatan yang diberikan kepada dewasa dengan diabetes mellitus menggunakan metode yang komprehensif sesuai dengan penatalaksanaan DM, dan memanfaatkan berbagai macam media yang lebih interaktif dan aplikatif, baik untuk tenaga kesehatan sendiri maupun dewasa dengan diabetes mellitus yang berfokus untuk meningkatkan pengetahuan, sikap, keterampilan, dan kontrol gula darah. Pelayanan keperawatan kesehatan masyarakat perlu dibentuk dalam setiap tatanan pelayanan kesehatan guna dapat lebih tepat menentukan intervensi apa yang sesuai dengan masalah masyarakat.

13 Graceistin Ruben, Julia Rottie, and Michael Y Karundeng, "Pengaruh Senam Kaki Diabetes Terhadap Perubahan Kadar Gula Darah Pada Pasien Diabetes Melitus Tipe 2 Di Wilayah Kerja Puskesmas Enemawira," eJournal Keperawatan (eKp) 4 (2016): 1-5.

${ }^{14}$ Claudia Fariday Dewi, "Effects of Progressive Muscle Relaxation Intervention With Music and Aromatherapy on Decreasing Stress Level Among Teachers," Nurse Media Journal of Nursing 8, no. 2 (2019): 71.

15 Wei Guo et al., "Novel Rhynchophylline Analogues as Microvascular Relaxation Agents for the Treatment of Microvascular Dysfunction Caused by Diabetes," European Journal of Medicinal Chemistry 139 (2017): 657-664. 
ENGAGEMENT

Jurnal Pengabdian kepada Masyarakat Volume 04, Number 01, May, 2020, pp. 201 - 211

\section{Daftar Referensi}

Abdulah, Deldar Morad, Alan Bapeer Hassan, Farsat Saeed Saadi, and Ary Habeeb Mohammed. "Impacts of Self-Management Education on Glycaemic Control in Patients with Type 2 Diabetes Mellitus." Diabetes and Metabolic Syndrome: Clinical Research and Reviews 12, no. 6 (2018): 969-975.

Alfred, Danita, Jenifer Chilton, Della Connor, Belinda Deal, Rebecca Fountain, Janice Hensarling, and Linda Klotz. "Preparing for Disasters: Education and Management Strategies Explored." Nurse Education in Practice 15, no. 1 (2015): 82-89.

Borzekowski, Dina L.G. "A Quasi-Experiment Examining the Impact of Educational Cartoons on Tanzanian Children." Journal of Applied Developmental Psychology 54, no. March 2017 (2018): 53-59.

Chai, Sanbao, Baoting Yao, Lin Xu, Danyang Wang, Jianbin Sun, Ning Yuan, Xiaomei Zhang, and Linong Ji. "The Effect of Diabetes Self-Management Education on Psychological Status and Blood Glucose in Newly Diagnosed Patients with Diabetes Type 2." Patient Education and Counseling 101, no. 8 (2018): 1427-1432.

Davis, Scott A, Delesha Carpenter, Doyle M Cummings, Charles Lee, Susan J Blalock, Jennifer Elissa Scott, Lisa Rodebaugh, B S N Rn, Stefanie P Ferreri, and Betsy Sleath. "Patient Education and Counseling Patient Adoption of an Internet Based Diabetes Medication Tool to Improve Adherence: A Pilot Study." Patient Education and Counseling 100, no. 1 (2017): 174-178.

Dewi, Claudia Fariday. "Effects of Progressive Muscle Relaxation Intervention With Music and Aromatherapy on Decreasing Stress Level Among Teachers." Nurse Media Journal of Nursing 8, no. 2 (2019): 71.

Dinkes. "Profil Kesehatan Kota Depok 2015” (2016).

Fan, Lifeng, R N Cde, and Souraya Sidani. "Factors Influencing Preferences of Adult with Type 2 Diabetes for Diabetes Self-Management Education Interventions." Canadian Journal of Diabetes (2018).

Guo, Wei, Huikun Zhu, Zhijun Wang, Ji An Chen, Jian Wu, Yizhun Zhu, and Xianfeng Gu. "Novel Rhynchophylline Analogues as Microvascular Relaxation Agents for the Treatment of Microvascular Dysfunction Caused by Diabetes." European Journal of Medicinal Chemistry 139 (2017): 657-664.

Ishak, Nor H., Siti S. Mohd Yusoff, Razlina A. Rahman, and Azidah A. Kadir. "Diabetes Self-Care and Its Associated Factors among Elderly Diabetes in Primary Care." Journal of Taibah University Medical Sciences 12, no. 6 (2017): 504-511.

Kamitani, Emiko, Yoshimi Fukuoka, and Carol Dawson-Rose. "Knowledge, Self-Efficacy, and Self-Perceived Risk for Cardiovascular Disease among Asians Living With HIV: The Influence of HIV Stigma and Acculturation." Journal of the Association of Nurses in AIDS Care 26, no. 4 (2015): 443-453.

Pender, Nola, Carolyn Murdaugh, and Mary Ann Parsons. Health Promotion in Nursing Practice. Edited by Erin Sullivan. Seventh. United States of America: Julie Levin Alexander, 2015. 
Rahajeng, Ekowati. "Pedoman Teknis Surveilans Faktor Risiko PTM Berbasis Posbindu." Kemenkes RI, no. Maret (2014).

Ruben, Graceistin, Julia Rottie, and Michael Y Karundeng. "Pengaruh Senam Kaki Diabetes Terhadap Perubahan Kadar Gula Darah Pada Pasien Diabetes Melitus Tipe 2 Di Wilayah Kerja Puskesmas Enemawira." eJournal Keperawatan (eKp) 4 (2016): $1-5$.

Soltanian, Ali Reza, Shiva Borzouei, and Mohammad Afkhami-Ardekan. "Design, Developing and Validation a Questionnaire to Assess General Population Awareness about Type II Diabetes Disease and Its Complications." Diabetes and Metabolic Syndrome: Clinical Research and Reviews 11 (2017): S39-S43.

Stanhope, Marcia, and Jeanette Lancaster. Foundations of Nursing in The Community: Community-Oriented Practice. by Mosby, Inc., an affiliate of Elsevier Inc., 2016. 
